\title{
Outreach of Financial Institutions, Access to Information and Energy Substitutability: A Case for Photovoltaic Energy Preferences in Agriculture Sector of Pakistan
}

\author{
Syed Toqueer Akhther and Raja Ramz Ullah
}

\begin{abstract}
The study aims at testing the proposition that how outreach of financial institutions as well as the access to information about alternate sources of energy affect inclination towards energy substitutability, significantly or insignificantly. Furthermore, the study also tests a second hypothesis that government's decision to associate income tax with level of energy consumption from electricity distribution companies will affect agriculturalist's inclination to comply for the process of energy substitutability. Important stimuli for energy preferences such as information regarding alternate sources of energy and installment costs of efficient photovoltaic energy systems on the farm are also incorporated. Generalized Method of Moments was used to comprehensively establish the relationship between outreach of financial institutions as well as access to information about energy substitutability, upon the intent of farmers to switch towards other sources of energy. The results show that the policy to link energy consumption and income tax can be a good policy tool to ensure that the ongoing process of energy substitutability is sustainable in the long term. A need for state sponsored micro finance schemes as well as the provision of Amber \& Green Subsidy, can create ease for farmers in attaining photo voltaic energy systems to ensure energy efficient solutions. Robust regression was used keeping in view the apprehension about the possible existence of heteroscedasticity in cross sectional data. Furthermore it can also be used in order to identify important observations.
\end{abstract}

Index Terms-Energy efficiency, financial exclusion, technology information, robust regression.

\section{INTRODUCTION}

The following section incorporates essential evidence of the current energy scenario in Pakistan. Energy policies and reforms in ensuring sustainable supplies and in facilitating energy substitutability have also been critically reviewed. Lastly we look into the research concerns and study objectives.

A. An Overview of Energy Supplies and Energy Poverty in Agriculture Sector of Pakistan: Energy Prices, Shortfalls and Opportunity Cost of Pricing and Shortages

Pakistan's economy like many of other developing economies around the world has suffered immensely at the hands of massive power outages. With a rapidly growing rate of energy demand backed up by inconsistent power supply, the situation is set to post energy shortfalls. Pakistan has set

Manuscript received April 30, 2015; revised September 17, 2015.

The authors are with the Lahore School of Economics, Lahore, Pakistan (e-mail: syedtoqueer.research@gmail.com, ramzullahraja@gmail.com). up electrical energy generation capacity of $23,048 \mathrm{MW}^{1}$. The middling demand is $17,000 \mathrm{MW}$ whereas the shortfall is approximately between the range of 4,000 and $5,000 \mathrm{MW}^{2}$. The country's energy mix is dominated with the use of inefficient and costly non-renewable sources of energy. Currently the installed energy production ability consists of; hydro 6,858 MW, thermal 15,440 MW and nuclear $750 \mathrm{MW}$ consequently accounting for the primary sources of energy. Hence the hydropower capacity accounts for 29.7 percent, thermal 67.0 percent and nuclear 3.3 percent $^{3}$. Yet due to various inefficiencies, electricity production is less than half of the production capacity.

Inconsistent energy policies and lack of long-term planning over the past decade has caused massive public outrage which has forced the government to resort to pricey generation of electrical energy at around Rs 12 / unit. Energy consumption was at 40,185 million TOEs ${ }^{4}$ during the year 2013-14 as compared to 40,026 million TOEs in $2012-13$ posting a growth of $0.4 \%$. In order to carter to the exceeding demand, Pakistan has witnessed an increased reliance on conventional energy means such as the costly thermal fuel supply, that accounts to around $44 \%$ of total energy production. $\mathrm{RFO}^{5}$, $\mathrm{HSD}^{6}$ are regarded as the main sources of thermal electricity generation in Pakistan. Their price unit is in the bounds of Rs 12 per unit for mixed, to Rs 17 per unit for RFO, and Rs 23 per unit for HSD which is considered extremely pricey (National Power Policy 2013) ${ }^{7}$. Dependence on such costly fuel sources has strained Pakistan to produce electricity at rates that are not only excessive to the purchasing power of the businesses but also to the common people.

In agriculture sector of Pakistan the primary inputs for agronomic output are available on time at a judicious cost, potentially, agriculture sector has the capacity to reduce poverty levels and drive overall economic growth in Pakistan. However the water accessibility situation in the country seems to have deteriorated over the past decade which has hampered

${ }^{1}$ Highlights of Pakistan Economic Survey 2013-2014 (Page-16)

${ }^{2}$ Ministry of Planning and Development. (2014). Energy Sector. Energy Security and Affordability (Chapter 10-Page-127)

${ }^{3}$ Highlights of Pakistan Economic Survey 2013-2014 (Page-16)

${ }^{4} \mathrm{TOE}$ : Is an abbreviation of Tonne of oil equivalent (toe). It is defined as per unit amount of energy released by burning one tonne of crude oil.

${ }^{5}$ RFO: This is an abbreviation for residual fuel oil. Also known as heavy fuel oil. It is the remainder of the crude oil after gasoline and distillate fuel oils have been extracted through distillation. It fuels thermal power stations

${ }^{6} \mathrm{HSD}$ : It is an abbreviation of High speed diesel used for electricity generation. Gas Turbines requiring distillate fuels normally make use of HSD as fuel.

${ }^{7}$ Ministry of Water and Development. (2013). National Power Policy (Page-3) 
the growth of the agriculture sector. As a result, most the agriculturist are left dependent upon ground Iwater which has to be pumped by tube wells that are either run on electricity obtained from WAPDA ${ }^{8} /$ DISCOs $^{9}$ or they are fueled by non-renewable energy sources such as petrol and diesel. Limited outreach of Pakistan's energy distribution frame work for rural areas dictate that the agriculturalists pay substantial sums of money to attain access to the national grid. Government has planned agrarian subsidies along a uniform electricity tariff rate of Rs 10.5 per unit for tube wells used for agricultural purposes ${ }^{10}$, however an amount of Rs 22 billion will be prerequisite in order to foot the electricity subsidy bill. This will be Rs3.5 billion higher than last year. Considering the debt situation of the country, such policies are not sustainable for the national treasury.

\section{B. A Critical Review of Energy Policies and Reforms in Ensuring Sustainable Supplies and in Facilitating Energy Substitutability}

With the new National Energy Policy 2013-2018 in contention, energy sector subsidies would again be reestablished, especially for the agriculture sector. Total riddance from power outages would only be possible in the year 2017 with excess power production from 2018. With a purpose to increase efficiency, the administration has decided to denationalize government owned power plants along with some distribution companies; DISCOs. Materialization of regional transmission and power trading frameworks has also been proposed.

Amidst all the restructuring of the bodies related to the power generation and distribution, sustainability of electricity supply, let alone "efficient energy" ${ }^{11 ", ~ h a s ~ y e t ~ a g a i n ~ b e e n ~}$ overlooked. Key problems such as improving the process of collection of receivables and avoiding the buildup of circular debt have not been properly addressed, emphasis is more upon retiring the already existing debt. Other worrying concerns such as power theft and low recovery rate of receivables have reportedly caused a loss of Rs.260 billion to the energy sector which has depressed the rate of investment in this segment (Institute for Policy Reforms 2014). Because of the energy mix for Pakistan, presently expensive and non-renewable fuels such as diesel, petrol and natural gas are in use. Nonetheless no policies have been implemented at a micro level that can promote the usage of energy efficient photo voltaic energy systems for agricultural purposes in Pakistan. Such diversification of energy mix can potentially ensure uninterrupted supply of water for the cultivation of crops and also lower a farmer's overall expenditure upon energy obtained from the national grid in the long run, hence depressing the yawning energy shortfall.

\section{Research Concerns and Study Objectives}

The study aims at testing the proposition that as a farmer faces greater levels of difficulty in the process to attain additional finance for their input, their inclination towards

\footnotetext{
${ }^{8}$ WAPDA: Water and Power development authority of Pakistan

${ }^{9}$ DISCOs: Other Power Distribution Companies

${ }^{10}$ Ministry of Finance. (2014). August 25, 2013 (Press Release INo.305)

${ }^{11}$ Energy Efficiency: Reduce the amount of energy consumed while maintaining the level of output.
}

energy substitutability will be affected significantly or insignificantly. Furthermore, the study also tests a second hypothesis that government's decision to associate income tax with level of energy consumption from WAPDA/DISCOs will affect agriculturalist's inclination to comply for the process of energy substitutability ${ }^{12}$.

Implications of various levels of access to information regarding alternate energy sources of energy and related technology upon energy substitutability are also examined. Furthermore energy choices are analyzed with respect to the high initial installment cost of photo voltaic energy systems.

\section{PROPOSED FRAMEWORK OF ANALYSIS AND MODELING CHOICES}

Outreach of financial institutions along with situation of financial exclusion ${ }^{13}$ and impact upon intent of energy substitutability has been reflected upon. Other factors such as flow of technological information and reasons for its bottlenecks affecting energy substitution are also discussed. Later, an overview of data instruments for quantifying energy substitutability and financial exclusion has been given. This is followed by a discussion on survey design along with sampling framework and field work for the study. Lastly, specification of competing econometric models is revealed with discussion on model consolidation tests.

\section{A. An Overview of Theories of Energy Substitutability and Energy Mix}

Thus, according to H. E. Goeller and Alvin M. Weinberg, we can study the exhaustion of resources and substitution in three unalike phases lasting over different time periods. First phase, which assuredly persisted for 30 to 50 years (1978, when the study was published), was a continuance of consumption rates of the nonrenewable resources. Moving on to the second phase, the population would still be reliant on non-renewable raw materials that were earlier discovered, though fossil fuels such as coal, oil and gas would be scarce and their costs would rise. Consequently society's preferences regarding that raw material would start to change into much greater usage of that resource. Region either This phase might last several hundred years (as per the estimated expected future consumption rates at that time). Finally in third and the last phase, which happens to be the Age of Substitutability, all the sources of fossil fuel would be diminished and civilization would be established almost wholly on resources that are practically unlimited in nature [1].

As per the rudimentary argument that, as a society distinguishes limits to inorganic resources, the circumstances under the third and last phase would not be significantly dissimilar from the present-day situation. This is because as of now, civilization has the actual probability of persisting in the age of substitutability and not entirely unsettling the societal and economic arrangements. However, to attain this state without vast societal disturbance we need to have exceptional far-sightedness and preparation.

\footnotetext{
${ }^{12}$ Energy Substitutability: Ability to substitute one source of energy with another.

${ }^{13}$ Financial Exclusion: Inability to access financial services from formal sources.
} 
Over the years, many studies have been conducted in order to investigate the substitutability of energy and capital. This theory of substitutability gained momentum after the advent of the first oil price shock which made the economist realize its significance in times to come. This led to numerous other researches which have appeared in the literature. Some studies suggest that estimations of the elasticity of substitution are extremely variable among various segments, nations and also time periods.

For instance studies by (Anderson, 1981) suggests that approximations of the cumulative elasticity of substitution between capital and energy for U.S. manufacturing doubled between the year 1960 and 1971 [2]. Another conducted research (Denny, 1981) shows estimates at the double figure level as far as Canadian and U.S. industries are concerned [3].

In numerous different types of industries capital and energy are discovered to be substitutes in one country while complements in other. However this is not conclusive because there seems to be a certain contradiction among the estimates made through time-series data and those attained by means of cross-sectional data. In the time series data, larger fraction of the estimates specify that capital and energy are complements, while the findings from cross-sectional maintain that the relationship is that of the substitutes.

Factor substitution and technological advancements have allowed the developed countries to tackle the problems of rising energy prices. As supported by literature (Gopalakrishnan, 1987) energy-nonenergy substitution process is one of the reasons why the agriculture sector of the US is resilient to cope with rising fuel prices. Contrariwise, in order for the industrial and economical wheel to keep spinning, most of the developing countries have always been dependent upon costly fossil fuel to fulfill their energy demands. With ever depleting fuel reserves and low rates of water conservation, these economies are fast running out of options to diversify their energy mix [4].

Various policies are drafted to engage various market instruments that are considered as inducements for the utilization of most economically efficient technologies (Kerr, 2006) [5].

Looking at the forecasted trends in literature (Georgia Destouni, 2010), renewable energy sources are estimated to deliver around $35 \%$ of the worldwide energy supply and approximately half of power generation by 2050 [6]. The use of energy obtained through fossil fuel is therefore projected to keep on high levels. The administration needs to take stern action and come up with innovative plans for ensuring efficiency in usage and development, sufficiency and consistency of supply, and processes to minimize ecological impacts.

As far as the investor's confidence in the energy sector is concerned, a reliable and transparent structure needs to be made. An investment friendly frame work will ensure surge of investment into the energy sector which will in turn aid in increasing energy supply levels and help soothe price volatility. A supported by studies (A. Ercelawn, 2002) structure of the national energy policy should be such that it should entail various strategies to endorse energy efficiency and diversity which will consequently help in diminishing country's vulnerability to high oil prices [7].

\section{B. Outreach of Financial Institution, Financial Exclusion and Intent of Energy Substitutability}

Credit accessibility is a crucial aspect for a rural economy to thrive. Attainment of production inputs, modernization of processes, dealing with economic disparity, savings preferences, sharecropping agreements, farm land potency assessments are just a few essential cases of the extensive variety of scenarios that are expected to be closely stimulated by loaning and borrowing opportunities provided by the outreach of the financial institutions. Therefore, to make good use of any available credit opportunity, a good understanding of rural credit needs to be in place on behalf of the policy makers as well as the general public because studies suggest that advantages of financial liberalization have yet to penetrate the agricultural segment of developing countries such as Uganda (Marios Obwona, 2001) [8].

Just like any other country which considers agriculture as the "back bone" of their economy, convenience and accessibility of credit facilities are vital to meet financial requirements of the agronomic division. This is one of the imperative elements that are considered to play a central role in the growth and development of the agriculture sectors of South Asian economies.

India for instance planned the institutionalization of rural credit facility for rural financial inclusion. From the years 1950 's to 1980 s, it seemed that the objective to compete away the moneylender was being accomplished [9]. The portion of grower debt which was obtained from formal sources improved from $18 \%$ in $1961 / 62$ to $63 \%$ in $1981 / 82$, while the pooled share of landlord, farmer, specialized moneylender and trader credit reduced from $70 \%$ to $23 \%$ over the same time span. For operational, theoretical and contextual reasons, it is expected that the official statistics underestimated the relative portion of informal finance in whole of rural household debt [10].

However, moving on to 1991, in contrast to previous escalations, the portion of formal debt in total indebtedness for rural families had improved marginally up to $64 \%$. Further ten years down the time line, the portion of institutional loans dwindled to $57 \%$ by 2002 . Furthermore, debt obtained from moneylenders, also regarded as informal agents which were meant to be replaced through the institutionalization of credit, increased in total share of rural loans from almost $18 \%$ in 1991 to nearly $30 \%$ in year 2002 . Hence, after over a century of policy adjustments which were aimed to gradually institutionalize rural credit; approximately one-third of total rural debt is still obtained from the informal moneylenders. Interestingly the state of Andra Pradesh has the most concentration of Self-Help Groups, MFIs and Banks; however the state also contains the highest amount of rural non-institutional debt amounting to almost $73 \%$ and the highest proportion of rural moneylender debt of approximately $57 \%$ [11].

Other contemporary studies show that the core problem is that the credit which is distributed to the agriculturalists is not on the basis of time of sowing or other relevant practices. Furthermore, it is advised that the credit availability must be according to the input requirement of farmers without any sort of provision fees. Financial institutions offering agricultural loans should also have a regular check upon the performances 
of the loanee so that it can be assured that the credit being offered is utilized properly.

Such problems can be seen in other developing countries in the region as well. As "Evolution of rural informal financial institutions in South Asia" (Banik, 2003) points out that "credit" happens to be one of the least self-assuredly facets of a rural economy in Eastern India, Bangladesh and Nepal. The study reveals that informal credit markets are an essential part of the rural fiscal structure in South Asia. Majority of the small and meager debtors choose the informal credit markets as they consider it to be the most feasible source of finance in the medium term. One of the reasons for this is that loans acquired from the informal sector consist of very little transactional costs along with far lesser requirements to account for a borrower's risk premium. Henceforth it could be very beneficial if strategies are chalked out to reinforce the links between the formal and the informal sector, in the areas and sections in which competitive conditions are to be seen, while attaining full benefits of the lower transaction costs to "retail" credit. In effect, this methodology not only preserves the essential informality but also chooses what the masses consider reasonable as per their requirements. This approach would also enable the policy makers to fortify and develop the prevailing bonds between the two sectors [12].

Derived from social exclusion, the term "financial exclusion" is used to mention a situation where the populace has certain complications in accessing financial services as per their needs within the traditional market. As supported by research (Mahadeva, 2009), other than just absence of corporal access to monetary institutions, which happens to be one of the most significant restraining factor, lack of awareness, little earnings, social omission and illiteracy have been the constraints that have led to financial exclusion [13]. However, over the last decade or so, this state has gradually come into the consideration of the developed countries around the world as they dissect this problem and take it as a measure which has to be taken into account while trying to alleviate poverty and social exclusion.

Now discussing the intent of substitutability, studies have shown that with rising costs of energy, a rational consumer would look for an equivalent substitute in the long term. Taking developing countries into consideration (MAHMUD, $1988)^{14}$ points out that energy when considered as an input has a substantial part in the manufacturing process. He maintains that there is a potential of substitution between energy and other inputs [14].

\section{Technological Information, Information Bottlenecks and Intent of Energy Substitutability}

Technological progressions have allowed humankind to break through the Malthusian trap! It has taught man how to employ the least amount of raw materials while still generating the maximum output. Countries like German, Japan and Korea are a few prime examples of how technological advancements can allow producers to find the optimum amount of inputs and outputs. It is likely that most of the developed countries around the world have ample

\footnotetext{
${ }^{14}$ Energy substitution in Pakistan's manufacturing, Pakistan Economic and Social Review, Vol. 26, No. 1 (Summer 1988), pp. 57-64.
}

finances to fund research and development and consequently find new ways for lowering costs of production. However when it comes to developing countries such as Bangladesh, Nigeria etc, availability of finance for $R \& D$ might be a problem. This is where the term "transfer of information" comes into play regarding technological advancements.

Particularly talking about the energy sector, the need to diversify energy mix and lower input energy costs has made the civilization realize about the importance of utilizing non-renewable resources. Technology has now allowed us to utilize limitless and vast energy sources such as the solar energy. None the less, in order to utilize these resources, enormous capital and intellectual investment is required. Institutes like Asian Developing Bank, World Bank and other donor countries can help in the funding of such projects. However the transfer of intellect is not that simple. It can be made possible through informal channels by the mobilization of skilled labor from one area to another and by publications and discussions of such technological advancement within the general public. This is where the role of scientific and technical institutions and learned societies comes into play. In a nut shell, information regarding new technology can be made possible through written, verbal, and direct face-to-face interactions.

However, bottlenecks such as high costs of information transfer of technology due to patents, licenses and intellectual laws prevent smooth transfer of technology but rightly so. Nonetheless, countries have been dealing with situations in a very sensible manner that would benefit all the parties involved.

As the 1980s dawned, policymakers in India reduced the regulations on overseas technological collaboration. This led to a drastic upsurge in pure technology transfer contracts during the decade. Nevertheless, by 1991, the stringent policy of control of foreign ownership and import protection continued. Then came a paradigm shift as the policymakers introduced a set of differentiated policies which allowed foreign investors to buy a majority stake in numerous industries. Consequently, India now gives automatic authorization for $51 \%$ foreign equity sharing in 35 high-priority sectors; consent for higher equity sharing than this is taken into consideration case by case [15].

Therefore, it is proved that a resilient governmental will can ease the flow of information across various boundaries which could in turn be beneficial for the general public, especially when we are discussing the flow of scientific information regarding energy efficient technology.

\section{An Overview of Data Instruments for Quantifying Energy Substitutability and Financial Exclusion}

Researchers around the world have tried and tested various different models to quantify the usage of energy and account for its substitutability. The modern day literature entails certain instances where various methods of scaling and ratios have been formed to record different sources of energy along with their usage. For example in the research carried out (Hari Katuwal, 2009), impact of access to biogas plants in Nepal on an extensive series of outcomes has been examined [16]. The research is established on the respondent base of 461 biogas consumers who are situated in 15 districts. A before \& after 
comparison was observed with a time span of one day. The reported findings show that a $53 \%$ decrease in the use of firewood and an $81 \%$ reduction in the time spent on gathering firewood. A similar sort of study was carried out in the Peruvian Andes with a similar methodology was used which was based upon a smaller sample size of 12 consumers (Garfi', Ferrer-Mart1', Velo, \& Ferrer, 2012). The findings report that there is a $50 \%$ to $60 \%$ decrease in the consumption of firewood. Andrew Atkenson and Patrick J. Keho have incorporated models of energy which are used to structure and replicate low short-run and high long-run elasticities of energy in their research, Models of energy use (1999). The study was conducted to find out the "implications for capital and output as well as energy use in the time series and in the cross section". The model tells us that capital and energy are to be considered complementary and that capital is dependent upon the adjustment costs. Due to the presence of the adjustment costs, capital stock moves gradually over a period of time with respect to the variations in energy prices. Considering the positive relationship, energy also changes at a slow rate. However in the long run, along with the use of energy, the capital stock modifies with respect to permanent changes in energy costs.

In order to measure the extent of financial exclusion in Australia, The Centre for Social Impact (CSI) developed a methodology on behalf of the National Australia Bank (NAB). Financial exclusion was measured according to the level of product ownership for three main financial services, transaction accounts, credit cards and insurance. Australians over the age of 18 were included in the survey. Customers were classified into different categories of financial exclusion. Ranging from being financially Included (owning all three services), marginally excluded (lacking one service), severely excluded (lacking two services), fully excluded (lacking all three services). Based on this agenda, questions were fashioned within the Roy Morgan Research financial services database. The databank consists of data collected from 50,000 face to face interviews with people in Australia. The findings were weighted to depict geographic, age and sex distribution of the population as per the ABS statistics (National Australia Bank, 2013) [17].

\section{E. Survey Design, Sampling Framework, Field Work Model Specification and Modeling Choices}

They research questionnaire was specially designed to quantify data instruments that were expected to affect an agriculturists level of expenditure upon electricity obtained from the National grid through WAPDA/DISCOs, hence it is the regressand. The variations in expenditure would then be used to observe changes in energy preferences of the grower as the regressors change. For the research, the regressand is quantified through a ratio scale. A ratio scale from 0 to 10 representing levels of energy expenditure was made, 0 being the point where the farmer has no expense related to energy obtained from WAPDA/DISCOs and 10 being the point where a grower's total energy expenditure is spent on obtaining energy from the national grid. Values between 0 and 1 will represent a farmer's mix of energy.

Non probability sampling technique, convenience sampling was used while selecting the sampling units for the process of questionnaire sampling. Questionnaire sampling was used in the research while the sampling units were selected on the basis of convenience.

Moving on towards the quantification of regressors, an agriculturist's willingness to pay for the process of substituting conventional with energy efficient photovoltaic energy systems is measured by categorizing the respondents into 5 different categories. Classification ranges from those farmers who have zero inclination to pay, to those who are ready to invest PKR 0.5 million o below, above 0.5 million and below 1 million, above 1 million and below 1.5 million and finally 1.5 million or above. Each of these categories was assigned coding from 1 to 5 representing lowest to highest willingness to pay for the process of substitution.

Access to information regarding alternative sources of energy was quantified by recording the respondent's answers on a scale of 1 to 5.1 demonstrating the lowest level of information access whereas 5 representing the highest level. The coding was done in view of the responses we got.

Availability of finance was quantified by categorizing the farmers according to their preferred source of finance for their inputs. There were 4 classifications, each representing the level of difficulty to attain finance according to the terms and conditions associated to that particular source. First option, "own finance" was considered the easiest source of finance as it had no strings or obligations attached. Then came "Loans from banks", this entailed all agricultural credit schemes that the government and other micro finance institutes had to offer at a very less interest rate. The third category, "local money lenders" as the name suggests entails finances that can be obtained from "informal sources". Growers who fall into this particular category might be suffering from financial exclusion. This phenomenon is seen throughout sub-continent and is discussed with great detail in the literature. Finally the farmers who have to sell their assets to finance their inputs come under the folds of "other sources". Thus coding is done according to the category a respondent falls in.

Moving on to the next variable, which happens to be concerned with the method of pricing an agriculturist has preferred when given the opportunity to employ efficient photo voltaic energy systems for their agricultural needs. It is denoted by "InstallCost" that is installment cost for the energy systems. Each option in the questionnaire represents the level of installment cost (low, moderate and high) which was inversely proportional to the running cost. For example if the respondent chose high installment cost, which is option 3, then as per the costing preference he/she will expect to incur low running cost in the future and vice versa. Option of choosing "Moderate installment cost along with moderate running cost" has also been given for those farmers who prefer to choose options other than first and last. Keeping our last model specification in mind, i.e. "GovtPolicy", it is quantified by simply asking the respondents whether or not the government's decision to associate income-tax with energy consumption from WAPDA/DISCOs stimulate their decision regarding the adoption of efficient energy technology.

The responses were coded as 1 if "yes" and 0 if "no". Responses from 35 agriculturists where recorded in the study. In order to avoid territorial biasness, respondents from 
different provinces and regions of Pakistan were interviewed.

\section{F. Mathematical Form of Primary Model and Competing Model}

Intent of energy substitutability $=\beta_{0}+\beta_{1}$ (Willingness to pay for the process of energy substitutability) $+\beta_{2}$ (Access to Information regarding alternate sources of energy) $+\beta_{3}$ (Difficulty in attaining finance for inputs) $+\beta_{4}$ (Impact of government's decision to associate income tax with level of energy consumed from the national grid) $+\beta_{5}$ (High Installment Cost of photo voltaic energy systems) $+\beta_{6}$ (Constant)

$$
\partial Y / \partial x_{1}=\partial \text { ExpedOnDISCOs } / \partial W T P=\beta_{1}
$$

$\beta_{1}$ estimates a change in ExpedOnDISCOs caused by a unit change in willingness to pay for the process of substituting conventional with efficient photo voltaic energy systems.

$$
\partial Y / \partial x_{2}=\partial \text { ExpedOnDISCOs } / \partial \text { AccessInfo }=\beta_{2}
$$

$\beta_{2}$ estimates a change in ExpedOnDISCOs caused by a unit change in the farmer's level of access to information regarding alternate sources of energy.

$$
\partial Y / \partial x_{3}=\partial E x p e d O n D I S C O s / \partial A v b o f F i n=\beta_{3}
$$

$\beta_{3}$ estimates a change in ExpedOnDISCOs caused by a unit change in the farmer's level of difficulty faced in the process to attain finance for inputs.

$$
\partial Y / \partial x_{4}=\partial \text { ExpedOnDISCOs } / \partial \text { GovtNewPolicy }=\beta_{4}
$$

$\beta_{4}$ estimates a change in ExpedOnDISCOs caused by a change in the impact upon farmer's level of energy consumption from WAPDA/DISCOs if the government decides to associate income tax with energy consumed from the national grid.

$$
\partial Y / \partial x_{5}=\partial \text { ExpedOnDISCOs /OInstallCost }=\beta_{5}
$$

$\beta_{5}$ estimates a change in ExpedOnDISCOs caused by a unit change in the installment cost of photo voltaic energy systems.

\section{G. Model Consolidation Test}

On the apprehension of hetereoskedasticity in the first estimated model, Ordinary Least Squares was not used in the study. Keeping in view the nature of cross sectional data and possible pattern and extent of different variations among various instruments, a robust regression seemed more suitable. More over a simple linear regression through the Generalized Method of Moments (GMM) was also used as a competing model to deal with the problem of hetereoskedasticity. Keeping in view similar kinds of scale as parts of questionnaire, there was an apprehension of multicollinerity. Therefore all estimated models are formally being tested for multicollinerity using variance inflation factor (VIF) and the results showed no such problem. For post-estimation purposes Breusch-Pagan/Cook-Weisberg test was conducted on the apprehension of heteroskedasticity in the model. Its null hypothesis states that hetereoskedasticity is present (null hypothesis rejected if $\mathrm{p}$-value is less than $5 \%$ ) however the test result showed a small chi2 value. None the less, generalized method of moments was used to apprehend hetereoskedasticity.

\section{PART 3: Model ESTIMATION AND ANALYSIS}

The mathematical form of the models is already been explained in E.2. In this section we further dissect the regression of the primary model as well as the competing model. Profile of survey respondents will be discussed along with key findings. Analysis of findings will further hone the rationale behind the study and its findings. Lastly conclusion and policy recommendations will allow us to propose energy sector reforms that can help in promoting efficient energy substitutability in the long-run.

\section{A. Econometric Models with Alternative Specifications and Model Consolidation Tests}

As per the regression results (Table I), willingness to pay for the process of substituting conventional with efficient photo voltaic energy systems is significant at 5\% in Robust Regression and also significant at $1 \%$ in the Generalized method of moments. However level of access to information regarding alternate sources of energy comes out to be significant in Robust Regression at 5\% but insignificant in the GMM. Difficulty in attaining finance for inputs is significant in both the models, $1 \%$ in GMM and 5\% in Robust Regression. Regression (Table I) also illustrates that the impact of government's decision to associate income tax with level of energy consumed from the national grid is significant in both the models at $5 \%$ whereas Installment Cost of photovoltaic energy systems is also significant at $1 \%$ in both Robust Regression and GMM.

\section{B. Profile of Survey Respondents, Key Findings}

35 farmers from across Pakistan were part of the research. All of these agriculturists had tube wells installed on their farm to cultivate their crops. Even though some of the respondents had diversified income sources, but agriculture was considered the primary base of wealth generation.

Robust regression was used in the study. It is regarded as an unconventional technique as compared to least squares regression especially when the dataset consists of outliers or other prominent observations. Furthermore it can also be used in order to identify important observations.

The results of the regression shows us that the greater a farmer's willingness to pay for the process of substituting conventional with energy efficient Photo Voltaic energy systems, the lesser will be his expenditure upon energy obtained from the national grid via WAPDA/DISCOs. Furthermore the findings show that if the farmer has greater access to information regarding alternative sources of energy, the lesser will be his outflow upon energy obtained from WAPDA/DISCOs.

Study results indicate that as the agriculturists face greater levels of difficulty in the process to attain additional finance for their input, their inclination towards energy 
substitutability will increase. However, by observing the responses, it seems that most of the farmers are substituting one non-renewable source of energy with other! E.g. electricity from WAPDA/DISCOs towards petrol or diesel powered energy systems. This can be seen as an opportunity for the government to promote sustainable energy sources in the form of solar energy systems which will aid in improving the efficiency levels of the process of energy substitutability in long term.

TABLE I: REGRESSION

Regressand = Intent of Energy Substitutability (Expenditure On energy from WAPDA/DISCOs)

Amount of expenditure on energy from the national grid out of total energy expenditure. (Ratio Scale)

\begin{tabular}{|c|c|c|}
\hline Regressors & $\begin{array}{l}\text { Robust } \\
\text { Regression }\end{array}$ & $\begin{array}{l}\text { Generalized Method } \\
\text { of Moment }\end{array}$ \\
\hline $\begin{array}{l}\text { Willingness To Pay for the process of substituting conventional with efficient photo voltaic energy systems. } \\
\text { (5 options listed from lowest (1) to the highest (5)) }\end{array}$ & $\begin{array}{l}-0.0643 * * \\
(-2.42)\end{array}$ & $\begin{array}{l}-0.731 * * * \\
(-4.25)\end{array}$ \\
\hline $\begin{array}{l}\text { Level of Access to Information Regarding Alternate Sources of Energy. } \\
\text { (Measured on a scale } 1 \text { being the lowest and } 5 \text { being the highest.) }\end{array}$ & $\begin{array}{l}-0.0706^{* *} \\
(-2.33)\end{array}$ & $\begin{array}{l}-0.0461 \\
(-1.51)\end{array}$ \\
\hline $\begin{array}{l}\text { Outreach of financial institution in terms of Financial Exclusion \& Financial Inclusion. } \\
\text { ( } 4 \text { sources of finance listed according to the difficulty level as per the terms and conditions. } 1 \text { lowest and } 4 \\
\text { highest difficulty.) }\end{array}$ & $\begin{array}{l}-0.1138^{* *} \\
(-2.45)\end{array}$ & $\begin{array}{l}-0.1228 * * * \\
(-4.43)\end{array}$ \\
\hline $\begin{array}{l}\text { Impact of government's decision to associate income tax with level of energy consumed from the national grid. } \\
\text { (Dummy variable, } 1 \text { is yes and } 0 \text { is no.) }\end{array}$ & $\begin{array}{l}-0.1568 * * \\
(-2.32)\end{array}$ & $\begin{array}{l}-0.1579 * * \\
(-2.16)\end{array}$ \\
\hline $\begin{array}{l}\text { Installment Cost of photovoltaic energy systems. } \\
\text { (Various pricing methods listed on a scale. } 1 \text { lowest installment cost and } 4 \text { is the highest.) }\end{array}$ & $\begin{array}{l}0.1577 * * * \\
(2.80)\end{array}$ & $\begin{array}{l}0.1673 * * * \\
(3.46)\end{array}$ \\
\hline Constant & $\begin{array}{l}0.8246^{* * * *} \\
(4.60)\end{array}$ & $\begin{array}{l}0.7644 * * * \\
(6.43)\end{array}$ \\
\hline Observations & 35 & 35 \\
\hline \multicolumn{3}{|l|}{ Goodness of Fit } \\
\hline $\mathrm{R}^{2}$ & 0.49083 & - \\
\hline Final GMM criterion & - & $3.78 \mathrm{e}-31$ \\
\hline Prob $>$ F & 0.0001 & - \\
\hline \multicolumn{3}{|l|}{ Model Consolidation Tests (same variables in primary and competing model) } \\
\hline Mean Variance inflation factor (VIF) & \multicolumn{2}{|l|}{1.14} \\
\hline Breusch-Pagan / Cook-Weisberg test for heteroskedasticity & \multicolumn{2}{|c|}{$\begin{array}{l}\operatorname{chi} 2(1)=0.32 \\
\operatorname{Prob}>\text { chi2 }=0.5693\end{array}$} \\
\hline
\end{tabular}

It can be seen that if the government associates income tax with the level of energy consumption which has been obtained from the WAPDA/DISCOs, agriculturists will look to diversify their current energy mix which will lower the overall load on the national grid hence shrinking the production and consumption gap of electricity.

Lastly a higher installment cost of energy efficient photovoltaic energy systems will discourage the farmers to diversify their current mix of energy which will in turn increase their expenditure upon the energy obtained through the national grid.

\section{Estimates of Competing Models and Model Consolidation Tests}

According to the estimated models applied in the study, the findings comes out to be as expected in accordance with the primary model. However "AccessInfo" came out to be insignificant when the regression was run using GMM. This might be because of the low number of respondents in the study. As mentioned earlier in the research concerns that the research in not funded by any party therefore, floating the questionnaire and carrying out face to face interviews with a large number of people was not possible.

\section{Analysis of Findings}

\section{1) Impact of outreach of financial institutions upon the intent of energy substitutability}

Pakistan ${ }^{15}$ is one of those countries that has one very low levels of financial penetration levels. According to state statistics, almost 56 percent of the adult population is completed excluded from any sort of financial service network, and 32 percent has to go through informal channels to acquire financial services ${ }^{16}$. Thus, developing microfinance framework in the country is of utmost importance to the success of any sort of poverty alleviation effort.

The findings of the research actually tells us a great deal about what a Pakistani farmer is going through at these harsh times of energy crisis. Due to ever rising energy bills and massive power outages, most of the agriculturists have diversified their energy mix. Since it is difficult to acquire additional finance, a farmer will shift from WAPDA/DISCOs to other relatively cheap non-renewable energy sources such as diesel (next best alternative for energy obtained from WAPDA/DISCOs) in order to supply uninterrupted power to their tube wells, at least. Taking the primary regression

\footnotetext{
${ }^{15}$ Pakistan Poverty alleviation fund. http://www.ppaf.org.pk/

${ }^{16}$ State Bank of Pakistan, Micro Finance Department, Strategic Framework for Sustainable Microfinance in Pakistan (Page-3)
} 
equation into consideration, even though it is difficult to attain additional finance for inputs, farmers have started to shift away from electricity that has been obtained from WAPDA/DISCOs towards other nonrenewable sources which are relatively easier and cheaper to substitute. This phenomenon has decreased the expenditure upon energy from WAPDA/DISCOs and increased farmer's dependency upon other non-renewable energy sources. This is one of the findings of the research. Energy shortage acts as a demand push effect towards energy diversification. Most of the agriculturists that were interviewed said that they were more than willing to diversify their energy mix. However in order to make the process energy substitutability "sustainable", the vacuum must be filled by a renewable energy source such as the energy efficient Photo voltaic systems.

\section{2) Technical information and energy substitutability preferences}

From the regression equation, it can be seen that as the level of technical information regarding alternate sources of energy increases, the farmer's energy substitutability and energy preferences (WAPDA/DISCOs to other sources) also increases. This is mainly due to rapid power outages and rising per unit cost of electricity in Pakistan. The energy obtained from the national grid is regarded as "expensive and insufficient in supply". Which means that if the farmer learns about any alternate source which is capable of consistently supplying energy for farm will diversify the current mix of energy. As a result, the expenditure upon energy obtained from the national grid will fall.

3) Impact of linking tax assessment with energy consumption upon intent of energy substitutability

It seems that most of the farmers would diversify their energy mix if the government decides to associate income tax with the level of energy consumption from the national grid. With rising input costs, an agriculturist would like to avoid paying additional money in the form of tax. However the same farmer would be more than willing to spend that same amount of tax money upon energy systems that might bring down their long term energy expenditure. Theoretically speaking, this might be a good policy tool for the government of Pakistan which can be used to easy the level of energy shortfall.

\section{CONCLUSION, RECOMMENDATIONS FOR ENERGY SECTOR REFORMS}

\section{A. Conclusion}

As per the conducted research, the farmers will be willing to diversify their energy mix if there is ample information regarding alternate sources of energy.

Difficulty in attaining additional finance for inputs will lower the expenditure upon energy from WAPDA/DOSCOs since a farmer will not be willing to pay heavy bills for a source that is considered inconsistent. However the farmer will still have to meet its energy demands by employing other non-renewable sources such as diesel and petrol. Hence, the current energy substitutability is not sustainable.

High initial installment cost of efficient photovoltaic energy systems will discourage the farmers to substitute their current conventional energy systems.

The process of energy substitutability can be boosted if the government decides to associate income tax with the level of energy consumption form WAPDA/DISCOs.

Greater the willingness of the farmer to pay for the process of substituting conventional with efficient photovoltaic energy systems, greater will be the level of energy substitutability in the agriculture sector of Pakistan.

\section{B. Recommendation for the Energy Sector}

Policy of "carrots and sticks" should be adopted by government to promote the usage of efficient Photo voltaic energy systems. For use of photovoltaic energy, farmers should be granted the Amber or Green Subsidy, which are also admissible by the WTO regime. To ensure that needed technologies may be available at reasonable prices, import tariffs should be abolished to lower the cost push effect upon the market price. Furthermore, micro finance schemes aimed at aiding the farmer to purchase photovoltaic energy systems should be introduced. For greater financial outreach, informal sources of finance such as the local money lender should be taken on board as well. If the policy is implemented, it is likely that the farmers who are currently substituting energy obtained from WAPDA/DISCOs with petrol or diesel, will look to employ energy efficient photo voltaic systems for long term sustainability.

\section{Limitations of Study}

The findings were based upon self-reported data which means that the responses might be subject to selective memory, telescoping, attribution and exaggeration references. There is also a possibility of survey error and findings of model may also be affected by that.

\section{REFERENCES}

[1] H. E. Goeller and A. M. Weinberg, "The age of substitutability," American Economic Association, vol. 68, pp. 1-11, Dec. 1978.

[2] R. G. Anderson, "On the specification of conditional factor demand functions in recent studies of U.S manufacturing," Modeling and Measuring natural Resource Substitution, Cambridge, MA: MIT Press, pp. 119-144, 1981

[3] M. Denny, M. A. Fuss, and L. Waverman, "Substitution possibilities for energy: evidence from U.S and Canadia manufacturing industries," Modeling and Measuring Natural Resource Substitution," pp. 230-257, 1981.

[4] C. Gopalakrishnan, "Energy-nonenergy input substitution in western U.S agriculture: Some findings," The Energy Journal, vol. 8, pp 133-145, 1987.

[5] S. Kerr, "Winds of change: the planning response to renewable energy in Scotland," The Town Planning Review, vol. 4, pp. 375-401, 2006.

[6] G. Destouni and H. Frank, Renewable Energy, Springer, vol. 39, pp $18-21,2010$

[7] A. Ercelawn and M. Nauman, "Asian development bank and Pakistan: case study of access to justice programme," Economic and Political Weekly, vol. 37, pp. 4561-4564.

[8] M. Obwona and A. Mugume, "Credit accessibility and investment decisions in Uganda's manufacturing sector: An empirical investigation," African Review of Money Finance and Banking, pp. 75-102, 2001

[9] C. Bell, "Interactions between institutional and informal credit agencies in rural India," The Economics of Rural Organisation, vol. 1 , pp. 186-213, 1993

[10] J. Howard and H.J Marcus, "A changing financial landscape in India: macro-level and micro-level perspectives," Financial Landscapes Reconstructed, pp. 305-324, 1994.

[11] All-India debt and investment survey, AIDIS, 1991 and 2002.

[12] A. Banik, "Evolution of rural informal financial institutions in South Asia," Savings and Development, vol. 27, pp. 361-375, 2003. 
[13] M. Mahadeva, "Understanding financial abandoning from a micro perspective: Policy responses," Savings and Development, vol. 33, pp. 405-430, 2009.

[14] S. Chisti and F. Mahmud, "Energy substitution in Pakistan's manufacturing," Pakistan Economic and Social Review, vol. 26, pp. 57-64. 1988

[15] M. Saqib, "An overview of the economic reform policy and FDI in india with special reference to the USA," Prospects of Foreign Direct Investment in India in Post Liberalisation Era, pp. 81-99.

[16] H. Katuwal and A. Katuwal, "Biogas: A promising renewable technology and its impact on rural households in Nepal," Renewable and Sustainable Energy Reviews, vol. 13, pp. 2668-2674, 2009.

[17] National Australia Bank, "Measuring financial exclusion in Australia," The Centre for Social Impact for National Australia Bank, 2013.

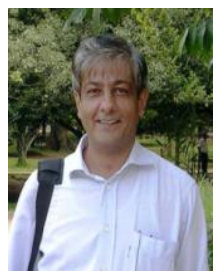

Syed Toqueer Akhter is an assistant professor of economics, at Lahore School of Economics, Pakistan. $\mathrm{He}$ has been engaged in teaching and research since 1992. His teaching interests include econometrics and research methodology. He has diversified areas of research interests. So far he has supervised some 328 theses as well as over 150 research papers. In 2014, 43 of his supervised researches were accepted in international conferences, in 18 different countries. In 2015, so far 38 research papers have been accepted in international conferences.

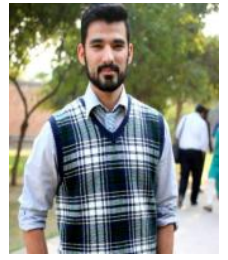

Raja Ramz Ullah is a student of Lahore School of Economics. Currently he is working as a research analyst. His academic majors are economics and finance. $\mathrm{He}$ has been involved in the energy and agriculture sectors of Pakistan. 